\title{
BIODIGESTÃO ANAERÓBIA NO TRATAMENTO DE RESÍDUOS LIGNOCELULÓSICOS ${ }^{1}$
}

Paulo André Cremonez ${ }^{2}$, Armin Feiden², Dilcemara Cristina Zenatti ${ }^{3}$, Mariele Pasuch de Camargo ${ }^{3}$, Willian Cézar Nadaleti², Eduardo de Rossi² ${ }^{2}$, Jhonathas Antonelli²

${ }^{1}$ Aceito para publicação no $3^{\circ}$ Trimestre de 2013

2 Universidade Estadual do Oeste do Paraná. Rua Universitária, 1220, Jd. Faculdade, Cascavel-PR, Brasil, CEP 85819-110 - email: pa.cremonez@gmail.com.

${ }^{3}$ Universidade Federal do Paraná. Rua Pioneiro, 2153, Jardim Dallas, 85950-000, Palotina, PR, Brasil.

\section{Resumo}

A demanda por energia cresce a cada ano, principalmente nos países em desenvolvimento, como o Brasil. A diversificação da matriz de energia é a chave para a segurança energética de uma nação. O objetivo do presente estudo foi obter informações sobre o processo de biodigestão anaeróbia e os principais fatores que o afetam, tal como das características dos materiais lignocelulósicos e seu potencial, visando à produção de biogás. O referido potencial de produção de biogás destes resíduos é comprovado, principalmente nos casos em que estes são atrelados a cadeia de produção de outro biocombustível. Não obstante, os processos de pré-tratamento destes resíduos ainda são dispendiosos e requerem o desenvolvimento de novas tecnologias que busquem baratear os processos e garantir sua eficiência.

Palavras-chave: biogás, energias renováveis, biomassa.

\section{ANAEROBIC DIGESTION IN THE TREATMENT OF LIGNOCELLULOSIC RESIDUES}

\begin{abstract}
Energy demand grows every year,especially in developing countries like Brazil.The diversification of the energy matrix is the key to energy security of a nation. The aim of this study was to obtain information on the process of anaerobic digestion and the main factors that affect it,such as the characteristics of lignocellulosic materials and their potential in order to produce biogas. The said potential of biogas production of this waste is proven, particularly in cases where these are linked to the chain of production of other biofuels.Nevertheless, the
\end{abstract}


processes of pre-treatment of such waste are expensive and still require the development of new technologiesthat seek to cheapen the process and ensure its efficiency.

Keywords: biogas, renewable energies, biomass.

\section{Introdução}

As discussões acerca da crise do petróleo tiveram início nas décadas de 70 e 80 quando se percebeu a necessidade de revisar o modelo energético mundial. Os países dependentes de fontes de energia externa passaram a buscar fontes alternativas desta, de modo a suprir, da mesma maneira, sua demanda interna (FERREIRA et al., 2006).

Considera-se como um dos fundamentos de sustentabilidade econômica de uma nação a sua condição de garantir logística e energia no desenvolvimento de sua produção, ao mesmo passo em que essa condição se dê de forma ecologicamente correta e segura. O Brasil é citado como referência mundial na produção de petróleo em águas profundas, na produção de etanol, de energia hidrelétrica e especialmente, na renovabilidade de sua matriz energética (TOLMASQUIM, 2012).

Diferentes fontes renováveis de energia obtiveram um aumento significativo de produção no país nos últimos anos. Observou-se um aumento de 4,7\% de produção de energia eólica no ano de 2009 com relação ao ano anterior, mesmo período no qual o biodiesel apresentou crescimento de 37,8\% no mercado interno. A atual matriz energética ainda teve aumento no percentual de produção de derivados de cana, com crescimento de 11 para $17 \%$ desde o ano 2000 (HALMEMAN e RODRIGUES, 2012).

Não obstante, a demanda por energia cresce a cada ano, principalmente nos países em desenvolvimento. No Brasil, nos próximos 10 anos, sugere-se um aumento de 5,3\% de energia ao ano, alcançando 372 milhões de TEP (Toneladas Equivalentes de Petróleo) até o ano de 2020 (TOLMASQUIM, 2012). Apesar da diversidade da matriz energética existente, 37,8\% desta em nosso país ainda é proveniente do petróleo (FERREIRA, 2007).

Devido à significativa produtividade, um grande volume de resíduos é gerado pelas agroindústrias, sendo este fator simultaneamente, uma oportunidade e um desafio em praticamente todas as regiões do país. As agroindústrias apresentam um sistema de gerenciamento ambiental e aproveitamento de subprodutos, contudo, o descarte de rejeitos ainda é uma problemática. No geral, estes subprodutos são queimados ou dispostos no ambiente de forma inadequada, provocando sérios danos ao meio ambiente (SATER et al., 2011; BRAND et al., 2002). 
A biomassa está entre as fontes para a produção de energia com maior potencial para os próximos anos. É considerada uma das principais alternativas para a diversificação da matriz energética, proporcionando a diminuição da dependência dos combustíveis fósseis (NETO et al., 2010).

Dentre as fontes de energia da biomassa insere-se o grupo de materiais lignocelulósicos, destacando-se deste modo, a biomassa florestal. A utilização da energia advinda desta fonte requer o conhecimento da composição química e das características físicas do material (SOUZA et al., 2012).

Diversas opções podem ser mencionadas para o aproveitamento de resíduos lignocelulósicos, como sua disposição em granjas, em indústrias de painéis de madeira reconstituída, compostagem e na geração de energia, seja esta através da queima direta (carvão vegetal), ou da transformação do resíduo em outras formas de combustível (QUIRINO, 2003). A Biodigestão anaeróbia é considerada um tratamento de alta eficiência e baixo custo, capaz de diminuir o teor de matéria orgânica de efluentes enquanto produz energia pela valorização do metano (ANGELIDAKI et al., 1993).

A biodigestão ocorre na ausência de oxigênio molecular, onde se tem consórcios de diferentes tipos de microrganismos interagindo estreitamente para promover a transformação de composto orgânico complexos, em simples. O processo de estabilização anaeróbia do reator pode ser descrita dividida em diversas formas e sendo dividida em 2, 3, 4 ou mais fases. Sendo a de 4 fases, a mais comum para explicar tais sucessão de eventos,divididos em hidrólise, acidogênese, acetogênese e metanogênese (MIN et al., 2013; PENG et al., 2013).

Além do biogás tem-se o biofertilizante como produto deste processo. $\mathrm{O}$ mesmo apresenta compostos bioativos que resultam de compostos orgânicos de origem animal e vegetal após a biodigestão. Estes dois produtos permitem o aumento da produção agrícola, agregando valor às cadeias produtivas, organizando e garantindo uma fonte de energia renovável e de baixo custo (COSTA, 2012; QUADROS et al., 2010).

O objetivo geral deste estudo foi levantar informações sobre o processo de biodigestão anaeróbia e os principais fatores que o afetam, tal como das características dos materiais lignocelulósicos e seu potencial, visando à produção de biogás.

\section{Biomassa Lignocelulósica}

A biomassa lignocelulósica inclui culturas energéticas, resíduos agrícolas florestais e a fração orgânica de resíduos urbanos. Esta última despertou interesse como matéria prima para 
o processo de biodigestão anaeróbia recentemente, devido à alta demanda de energia e grande disponibilidade de biomassa (MONTONERI, 2009).

Muitos produtos agrícolas e florestais são produzidos no Brasil, como em 2011, ano no qual o país atingiu 43,5 milhões de sacas de café, tornando-se o maior produtor mundial de uma das bebidas mais consumidas no mundo. O país ainda detém a $3^{\mathrm{a}}$ maior produção de milho do planeta e é responsável por mais da metade do açúcar comercializado em todo o mundo (MAPA, 2011), além de apresentar intensa produção de madeira. Todas as cadeias produtivas mencionadas geram elevadas quantidades de resíduos lignocelulósicos provenientes de bagaço, cascas e palhadas, como o café, em que $60 \%$ do peso bruto da semente corresponde a cascas (DELFIOL et al., 2012). Estes resíduos apresentam-se como potenciais produtores de bioenergia.

A lignocelulose é o principal recurso a ser empregado futuramente para a produção de energia, devido sua altíssima abundância e presença generalizada em resíduos agroindustriais e florestais. Na produção de etanol, por exemplo, grande parte de sua massa é composta de bagaço e palha que não são aproveitadas de forma otimizada nas indústrias (GNANSOUNOU, 2010; SIMS et al., 2010; SAGULA, 2012).

A composição química dos resíduos florestais é muito complexa, visto que seus componentes são constituídos de maneira desuniforme como resultado de sua estrutura (BROWNING, 1963). O principal componente da parede celular dos vegetais é a celulose, sendo o mais abundante composto orgânico encontrado na natureza. Além deste, a hemicelulose compõe parte da madeira e está sempre associada à lignina e celulose.

A lignina é um polímero aromático e tridimensional de elevado peso molecular, normalmente considerado indigestível e também inibidor da digestibilidade da parede celular de plantas, principalmente de forrageiras (TRUGILHO et al., 1996; FUKUSHIMA et al., 2000).

O empecilho nos processos de geração de energia que empregam microorganismos ocorre pela difícil degradabilidade destes compostos, visto que normalmente necessitam de prétratamentos termoquímicos e sacarificação enzimática (Figura 1), ambos de elevado custo (DA COSTA SOUSA et al., 2009; DERERIE et al., 2011). 
Figura 1. Alterações estruturais do complexo celulose-hemicelulose-lignina por pré-tratamento

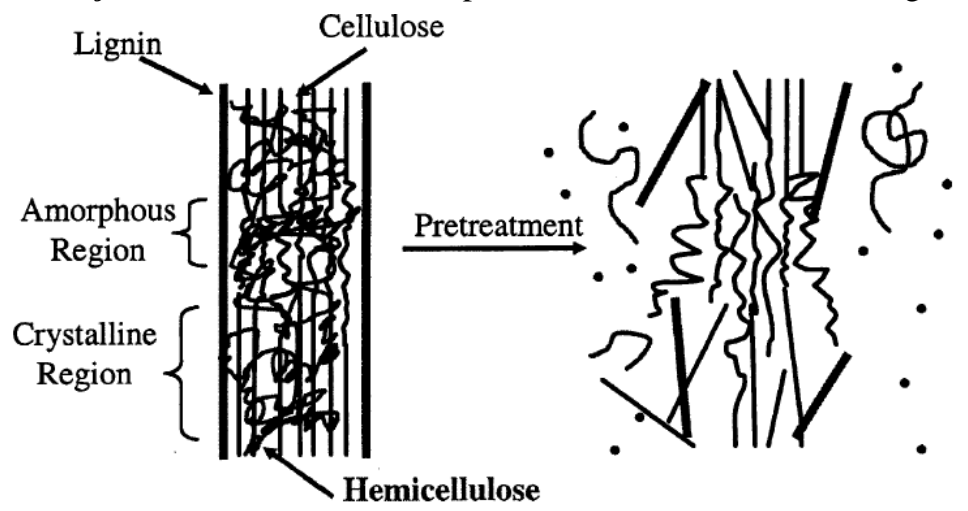

(MOSIER et al., 2005).

Os procedimentos de pré-tratamento de materiais lignocelulósicos podem ser realizados a partir de ácidos, bases, vapor, ou até mesmo a partir da combinação entre eles. Dentre os vários métodos de pré-tratamento, os mais utilizados são Expansão da fibra em amônia (AFEX), hidrólise, Processo em Separado de Sacarificação (SHF) e Fermentação Simultâneas (SSF). Tal procedimento separa a lignina da celulose e hemicelulose, deixando-os disponíveis para a biodigestão (SUN e CHENG, 2005).

\section{O processo de biodigestão}

O processo de biodigestão anaeróbia ocorre pela degradação, transformação ou decomposição da biomassa, realizada por microorganismos. Alguns produtos sintéticos também podem ser digeridos, os quais são conhecidos como produtos biodegradáveis (OLIVEIRA, 2005). A biodigestão ocorre em etapas distintas: hidrólise; acidogênese; acetogênese; e metanogênese (Figura 2).

A etapa de hidrólise ocorre pela quebra das cadeias carbônicas de proteínas, lipídios e carboidratos para compostos mais simples como aminoácidos, açucares, glicerol e ácidos graxos. A hidrólise de materiais lignocelulósicos ocorre de forma lenta e incompleta quando comparada a outras substâncias orgânicas (DEUBLEIN, 2011).

$\mathrm{Na}$ acidogênese, os produtos gerados no processo de hidrólise são convertidos em ácido acético, dióxido de carbono, ácidos graxos, dentre outros compostos e são absorvidos pelas células das bactérias fermentativas (KARAGIANNIDIS, 2012; FORESTI et al., 1999).

A transformação de ácidos graxos em ácido acético, liberando hidrogênio e $\mathrm{CO}_{2}$ é realizada na fase de acetanogênese. Nesta etapa, têm-se os substratos para a produção do metano (KARAGIANNIDIS, 2012). 
A última fase visa a produção de metano $\left(\mathrm{CH}_{4}\right)$ por dois grupos de bactérias, um deles que produz metano pela conversão do ácido acético (bactérias acetotróficas) e outro que o produz a partir da conversão de hidrogênio e dióxido de carbono (bactérias hidrogenotróficas). Esta fase é denominada metanogênese (ABBASI et al., 2012).

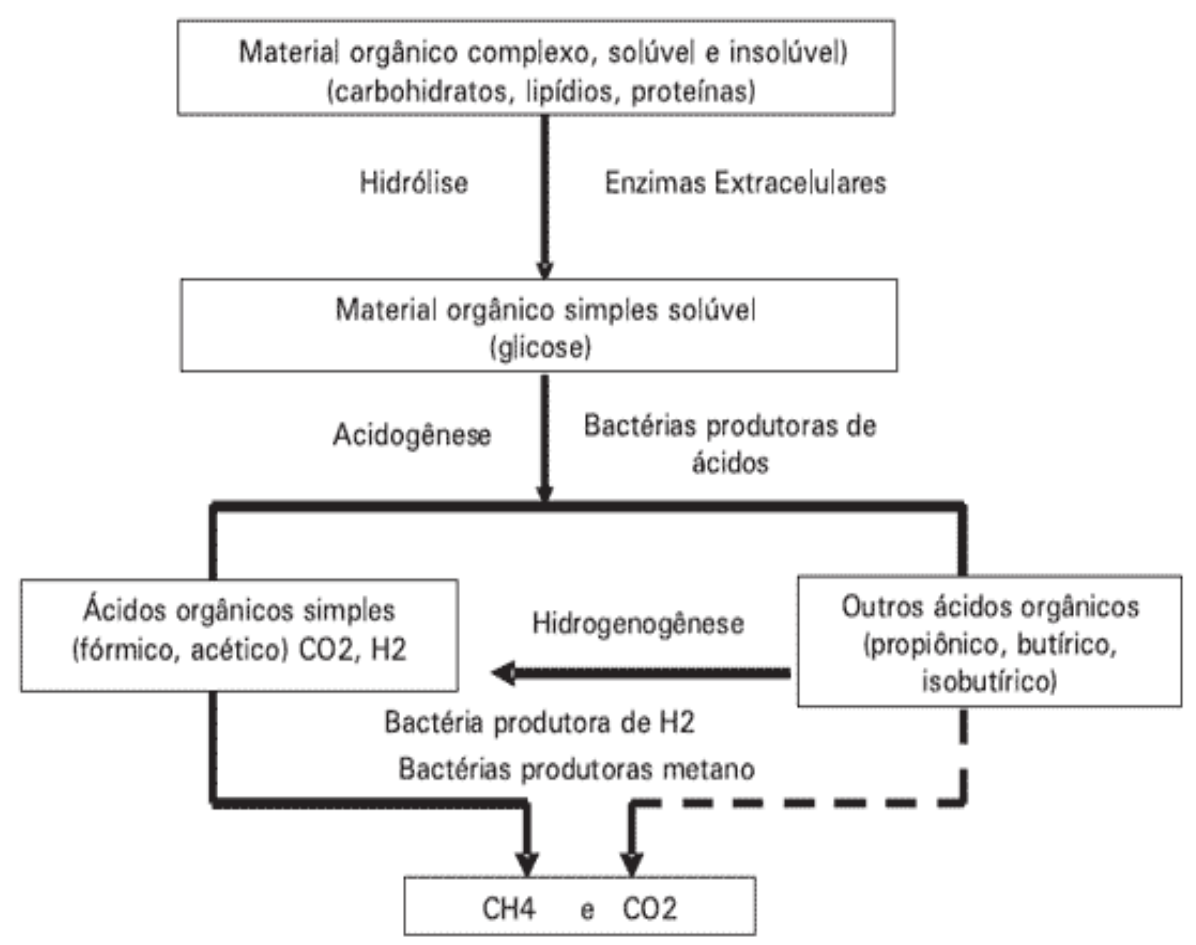

Figura 2. Etapas da biodigestão anaeróbia (Biodiesel.br, 2013).

\section{Fatores que afetam a Biodigestão}

Diversos fatores podem afetar o processo de biodigestão, sendo o mais importantes deles a temperatura (CHEUNBARN e PAGILLA, 2000). Para Salomon (2007), as faixas de temperatura associadas ao crescimento microbiano são classificadas em: psicrofílicas $\left(<20^{\circ} \mathrm{C}\right)$; mesofílicas $\left(20-40^{\circ} \mathrm{C}\right)$ etermofílicas $\left(>45^{\circ} \mathrm{C}\right)$. Em elevadas temperaturas a velocidade das reações biológicas é maior, resultandoem processosde eficiência elevada e menor Tempo de Retenção Hidráulica (TRH). A temperatura ideal no processo de biodigestão para a produção de biogás com elevado teor de metano na faixa mesófila compreende a faixa entre 20 e $40^{\circ} \mathrm{C}$, além de esta não requerer aquecimento ou resfriamento, podendo ser conduzida a temperatura ambiente buscando-se apenas manter as variações de temperatura preferencialmente inferiores a $3^{\circ} \mathrm{C}$ (BOND e TEMPLETON, 2011; PENG et al., 2013). 
O pH ideal para a biodigestão anaeróbia compreende 6,8 a 7,5, contudo, esta pode ocorrer de forma eficiente em faixa mais ampla (entre 6 e 8) em taxa menos elevadas (FORESTI, 1998). Moura (2012) afirma que em meios ácidos a atividade enzimática das bactérias é anulada e em meio significativamente alcalino a fermentação produz anidro sulfuroso e hidrogênio. Mediante a isto, assume-se que os valores de $\mathrm{pH}$ próximos a neutralidade são os mais indicados para este tipo de digestão.

A relação entre carbono e nitrogênio também é fator relevante nos processos de digestão, salvo que todos os organismos vivos precisam de nitrogênio na síntesede proteínas. No entanto, esta proporção deve ser a mais próxima do ideal, caso contrário, as bactérias não serão capazes de consumir todo carbono presente no meio e o desempenho do processo será baixo (SGORLON et al. 2011). O valor ótimo para relação C/N está entre 20 e 30 (REICHERT, 2005).

Segundo Silva (2001), quando se busca uma produção máxima de biogás pelo volume do biodigestor e unidade de tempo, a concentração de Sólidos Totais (ST) máxima deve ser menor que $8 \%$, faixa na qual também se facilita o movimento do material no interior do biodigestor, além de evitar entupimentos nos canos de entrada e saída do reator. Em casos em que as concentrações são maiores que $10 \%$, observa-se a diminuição da eficiência do biodigestor e o aumentoda probabilidade da criação de crostas.

Por fim, considera-se também o Tempo de Retenção Hidráulica (TRH), sendo este o tempo necessário para que o material passe pelo digestor, isto é, o tempo de entrada e saída dos diferentes materiais no digestor, como a água, sólidos e células (MOURA, 2012). Ainda segundo Gomes e Cappi (2011), o TRH está diretamente relacionado com o teor de sólidos totais do substrato e se refere ao tempo necessário para que o material seja degradado dentro do biodigestor.

\section{Biogás}

O Biogás é uma solução gasosa gerada a partir da biodigestão de biomassa em ausência de oxigênio e sua composição pode variar de acordo com as condições nas quais o processo fora realizado. Sua composição é de 40 a $70 \%$ de metano $\left(\mathrm{CH}_{4}\right), 30$ a $60 \%$ de dióxido de carbono $\left(\mathrm{CO}_{2}\right)$, e traços de sulfeto de hidrogênio $\left(\mathrm{H}_{2} \mathrm{~S}\right)$. O metano é o gás de maior interesse na mistura, sendo que quanto maior seu percentual, maior será o poder calorífico do biogás (OZTURK e DEMIRCIYEVA, 2013). 
Dependendo da diluição do biogás, o valor do Poder Calorífico Inferior (PCI) pode variar de 13.720 a $27.440 \mathrm{~kJ} / \mathrm{m}^{3}$, enquanto que o metano livre de impurezas apresenta PCI de $34.300 \mathrm{~kJ} / \mathrm{m}^{3}$, considerando pressão e temperatura normais (WALSH et al., 1989).

Além da comercialização do biogás, pode-se gerar renda a partir da comercialização de créditos de carbono pela não emissão de dióxido de carbono e venda do biofertilizante (lodo). Oliveira (2009) estudou a viabilidade de aplicação do biogás obtido a partir do tratamento de lixo urbano de uma cidade hipotética, juntamente com os créditos de carbono e biofertilizante comercializados, comprovando sua viabilidade, tanto do ponto de vista ambiental quanto econômico.

\section{Biodigestão de Materiais Lignocelulósicos}

Na biodigestão anaeróbia de biomassa lignocelulósica, a produção de metano é afetada pela composição e difícil degradabilidade da matéria lignocelulósica. Tal dificuldade se deve a natureza recalcitrante da lignina que reveste a celulose e a hemicelulose, sendo estas os principais carboidratos de interesse do processo. O teor de lignina, conteúdo de celulose e hemicelulose, volume de poros, tamanho das partículas, área superficial para reações enzimáticas e característica estrutural são os principais fatores que limitam a velocidade da taxa de hidrólise no processo de biodigestão de biomassa lignocelulósica (FRIGON e GUIOT, 2010; HIMMEL et al., 2007; MOSIER et al., 2005).

Durante os processos de pré-tratamento são liberados polímeros de 6 carbonos, facilmente hidrolisáveis e outros de 5 carbonos. Em sistemas de fermentação alcoólica, as leveduras tendem a utilizar preferencialmente as hexoses, consumo chamado de Repressão Catabólica (CCR). A referida preferência torna-se um desafio no controle e eficiência dos processos de fermentação com biomassa lignocelulósica e para tal, o processo de biodigestão e produção de biogás podem ser sugeridos como opção atrativa, visto que pode não somente produzir biogás a partir dos açucares restantes não fermentescíveis, como também balancear as concentrações de nutrientes do resíduo, tornando seu uso como biofertilizante bastante interessante (KIM et al., 2010; WILKIE et al., 2000; DERERIE et al., 2011).

Embora existam alguns estudos que comparem a quantidade de lignina na biomassa e a eficiência de degradabilidade, os dados encontrados na literatura ainda não são conclusivos. Chandleret al. (1980), encontraram em seu trabalho de degradação de materiais herbáceos, estrume e jornal uma relação linear inversa entre o teor de lignina e degradação de sólidos voláteis com coeficiente de correlação de $94 \%$, enquanto que em trabalho semelhante executado por Bjorndal e Moore (1985), o coeficiente apresentou resultados inferiores a $75 \%$. 
Em trabalho de Sapci et al. (2013), utilizando pré-tratamento através de explosão com vapor e microondas em palha de trigo, observou-se significativa melhora em processos de biodigestão e produção de metano.

Processos de biodigestão de materiais lignocelulósicos são indicados em sistemas de fermentação em fase sólida, onde os reatores operam com mais de $20 \%$ de teor de sólidos. Estes resíduos apresentam reduzido teor de umidade, além do fato que de a biodigestão sólida proporciona melhor aproveitamento do volume do reator, requer menos agitação e entrada de energia para aquecimento (GUENDOUZ et al., 2010; LI et al., 2011). A chave para a eficiência do processo é garantir a máxima área de contato do material com os microorganismos, garantindo a aceleração do processo. Além de microondas e explosão com vapor, enzimas hidrolíticas também são citadas como meio de quebra dos polissacarídeos.

Liew et al. (2012) testaram a degradação de biomassa lignocelulósica, incluindo palha de milho, palha de trigo, folhas e resíduos de jardim utilizando enzimas na hidrólise do material. As palhadas de trigo e milho, por apresentarem quantidades inferiores de lignina, proporcionaram maior geração de biogás do que as folhas e resíduos de jardim, $80 \mathrm{~L} / \mathrm{Kg} \mathrm{SV}$ e $70 \mathrm{~L} / \mathrm{Kg} \mathrm{SV}$ respectivamente, e superior degradação da biomassa, $34 \%$ e $41 \%$ contra $6 \%$ e $21 \%$. Como já mencionado em trabalhos anteriores, a produção de metano e teor de lignina apresentam relação linear inversa, enquanto que uma relação linear positiva é obtida quando se analisa a produção de metano com a quantidade de enzima adicionada.

Outra forma recentemente estudada em processos de hidrólise da biomassa é a clássica reação Fenton, processo de degradação não seletiva de compostos orgânicos aplicado em tratamentos de águas residuais altamente carregadas de indústrias (MERT et al., 2010; DE HEREDIA et al., 2001). Devido ao potencial oxidativo, os radicais presentes na reação têm capacidade de reagir com muitos compostos químicos conhecidos (Eq. 1 e 2).

$$
\begin{aligned}
& \mathrm{H}_{2} \mathrm{O}+\mathrm{Fe}^{2+} \rightarrow \mathrm{Fe}^{3+}+\mathrm{OH}^{-}+\mathrm{OH} \\
& \mathrm{Fe}^{3+}+\mathrm{H}_{2} \mathrm{O}_{2} \rightarrow \mathrm{Fe}^{2+}+\mathrm{HO}_{2}+\mathrm{H}^{+}
\end{aligned}
$$

Michalskaet al. (2012) comprovaram que o processo Fenton não é indicado no tratamento de materiais que apresentam teores muito elevados de lignina. Isto é, a baixa capacidade de degradação deste composto proporciona baixa liberação de açucares para a fermentação. Acompanhado de outros processos, a oxidação Fenton pode ser útil como prétratamento em processos de biodigestão pela sua baixa capacidade de degradar a celulose, o que resulta também em baixa perda de glicose. 
Dererieet al. (2011) realizaram um estudo com biodigestão de vinhaça e palha de aveia visando comparar o rendimento de produção de biogás. Antes do processo propriamente dito utilizaram três métodos de pré - tratamento: absorção com cal $\left(\mathrm{Ca}(\mathrm{OH})_{2}\right)$ e explosão a vapor com e sem impregnação com ácido sulfúrico. Os melhores rendimentos foram obtidos quando utilizado explosão a vapor da palha com ou sem tratamento ácido, com produções acima de 300 g CH $4 / g$ SV. O Poder calorífico superior da combinação da fermentação alcoólica e da biodigestão correspondeu a $9,8 \mathrm{MJ} / \mathrm{Kg}$ de palha de aveia seca com explosão a vapor e impregnação com ácido, 9,5 MJ/Kg para explosão sem impregnação e 9,6 MJ/Kg de palha utilizando cal como pré-tratamento. A produção de etanol aliada ao aproveitamento dos resíduos do processo na produção de biogás proporcionaram geração de energia superior a quando se produz um único biocombustível.

\section{Considerações Finais}

Os materiais lignocelulósicos estão entre os compostos mais abundantes presentes de natureza e apresentam grande potencial na produção de biogás, principalmente quando atrelado a outras cadeias de produção de biocombustíveis. Entretanto, para que os processos de biodigestão apresentem eficiência significativa, é necessário realizar um pré-tratamento visando a quebra de polissacarídeos compostos em substâncias mais simples. Diferentes trabalhos empregando o processo de biodigestão no tratamento de resíduos lignocelulósicos já foram desenvolvidos. Não obstante, os métodos de pré-tratamento do material ainda são dispendiosos e relativamente inviáveis para o cenário atual. Sendo assim, observa-se a necessidade do desenvolvimento de novas tecnologias que barateiem o processo e garantam sua eficiência.

\section{Agradecimentos}

Agradecimentos a CAPES pela bolsa de estudos concedida. 


\section{Referências}

ABBASI, T.; et al. Biogas Energy. 1st ed. New York, USA: Springer, 2012.

ANGELIDAKI, I.; AHRING, B.K. Thermophilic anaerobic digestion of livestock waste: the effect of ammonia. Appl. Microbiol Biotechnol, v.4, p.38-56. 1993.

BJORNDAL, K.A.; MOORE, J.E. Prediction of fermentability of biomass feedstocks from chemical characteristics. In: Smith WH, editor. Biomass energy development. New York: Plenum Press.1985, p.447-54.

BOND, T.; TEMPLETON, M.R. History and future of domestic biogas plants in the developing world. Energy for Sustainable Development, v.15, n.4, p.347-354. 2011.

BRAND, M.A.; MUÑIZ, G.I.B.; SILVA, D.A.; KLOCK, U. Caracterização do rendimento e quantificação dos resíduos gerados em serrarias através do balanço de materiais. Floresta, v.32, p.247-259. 2002.

BROWNING, B.L. The Chemistry of wood. New York, John Wiley \& Sons, 1963. 689p.

CHANDLER, J.A.; JEWELL, W.J.; GOSSETT, J.M.; VANSOEST, P.J.; ROBERTSON, J.B. Predicting methane fermentation biodegradability. Biotechnol Bioeng., v.22, p.93-107.1980.

CHEUNBARN, T.; PAGILLA, K. R. Anaerobic thermophilic/ mesophilic dual-stage sludge treatment. Environmental Engineering, v.126, p.796-801. 2000.

COSTA, L.V.C.; Produção de Biogás Utilizando Cama de Frango Diluída em Água e em Biofertilizante de Dejetos de Suínos. 2012. 90f. Tese (Doutorado Programa de Pós-Graduação em Energia na Agricultura), Faculdade de Ciências Agronômicas da Unesp. Botucatu - SP.

DA COSTA SOUSA, L.; CHUNDAWAT, S.P.S.; BALAN, V.; DALE, B.E. Cradle-to-grave assessment of existing lignocellulose pretreatment technologies. Curr. Opin. Biotechnol., v.20, p.339-347.2009.

DE HEREDIA, J.B.; TORREGROSA, J.; DOMINGUEZ, J.R.; PERES, J.A. Kinetic model for phenolic compound oxidation by Fenton's reagent. Chemosphere, v.45, p.85-90. 2001.

DELFIOL, D.J.Z.; OLIVEIRA-FILHO, J.P.; CASALECCHI, F.L.; KIEVITSBOSCH, T.; HUSSNI, C.A.; RIET-CORREA, F.; ARAUJO-JR, J.P.; BORGES, A.S. Equine poisoning by coffee husk (Coffea arabica L.).BMC Veterinary Research,v.8, n.4, p1-8. 2012.

DERERIE, D.Y.; TROBRO, S.; MOMENI, M.H.; et al. Improved bio-energy yields via sequential ethanol fermentation and biogas digestion of steam exploded oat straw. Bioresource Technology, v.102, p.4449-4455. 2011.

DEUBLEIN, D.; STEINHAUSER, A. Biogas from waste and renewable resources: an Introduction. 2nd edition. Germany: Wiley VCH. 2011. 
FERREIRA, L. L. Flexibilidade na utilização de diesel ou biodiesel, uma abordagem utilizando a teoria de opções reais. Dissertação de Mestrado. 2007. 54f. Fundação GetulioVargas - Rio de Janeiro 2007.

FERREIRA, Y.F.; LEÃO, K.P.; CASSANO, F.A.; OLIVEIRA, L.H. Biodiesel: potencializador da performance brasileira no mercado energético internacional. Revista Jovens Pesquisadores, v.3, n.2, p.55-70. 2006.

FORESTI, E. Notas da aula de Processos e Operações em Tratamento de Resíduos SHS705. Pós Graduação em Hidráulica e Saneamento na Escola de Engenharia de São Carlos. São Carlos. 1998.

FORESTI, E.; FLORÊNCIO, L.; HAANDEI, A.V.; ZAIAT, M.; CAVALCANTI, P.F.F. Fundamentos do Tratamento Anaeróbio. In.: CAMPOS, J. R. (Coord.). Tratamento de Esgotos Sanitários por Processo Anaeróbio e Disposição Controlada no Solo. $1^{\mathrm{a}} \mathrm{ed}$. Rio de Janeiro: RiMa Artes e Textos, p. 29-52. 1999.

FRIGON, J.C.; GUIOT, S.R. Biomethane production from starch and lignocellulosic crops: a comparative review. Biofuel Bioprod. Biorefin Biofpr, v.4, n.4, p.447-458. 2010.

FUKUSHIMA, R.S.; GARIPPO, G.; HABITANTE, A.M.Q.B.; LACERDA, R.S. Extração da Lignina e Emprego da Mesma em Curvas de Calibração para a Mensuração da Lignina em Produtos Vegetais. Rev. bras. zootec., v.29, n.5, p.1302-1311. 2000.

GOMES, F.O. de C.; CAPPI, N. Redução de Sólidos de Dejetos de Poedeiras em Biodigestores Operados com Diferentes Tempos de Retenção Hidráulica. In: Periódicos UEM. Anais... Encontro de Iniciação Científica, v.1, n.1. 2011.

GUENDOUZ, J.; BUFFIERE, P.; CACHO, J.; CARRERE, M.; DELGENES, J.P. Dry anaerobic digestion in batch mode: design and operation of a laboratory-scale, completely mixed reactor. Waste Manag., v.30, n.10, p.1768-71. 2010.

HALMEMAN, R.J.; RODRIGUES, S.A. Matriz energética brasileira: uma reflexão sobre a situação atual e possíveis riscos de "apagões". Bioenergia em revista: diálogos, ano 2, n.1, p.11-26. 2012.

HIMMEL, M.E.; DING, S.Y.; JOHNSON, D.K.; ADNEY, W.S.; NIMLOS, M.R.; BRADY, J.W.; et al. Biomass recalcitrance: engineering plants and enzymes for biofuels production. Science, v.315, p.804-807. 2007.

KARAGIANNIDIS, A. Waste to Energy: opportunities and challenges for developing and transition economies. 1st ed., London: Springer. 2012. 
KIM, J.H.; BLOCK, D.E.; MILLS, D.A. Simultaneous consumption of pentose and hexose sugars: an optimal microbial phenotype for efficient fermentation of lignocellulosic biomass. Appl Microbiol Biotechnol, v.88, p.1077-1085. 2010.

LI, Y.B.; PARK, S.Y.; ZHU, J.Y. Solid-state anaerobic digestion for methane production from organic waste. Renew. Sustain. Energ. Rev., v.15, n.1, p.821-6. 2011.

LIEW, L.N.; SHI, J.; LI, Y. Methane production from solid-state anaerobic digestion of lignocellulosic biomass. Biomass and bioenergy, v.46, p.125-132. 2012.

MERT, B.K.;YONAR, T.; KILIÇ, M.Y.; KESTIOGLU, K. Pre-treatment studies on olive oil mill effluent using physicochemical, Fenton and Fenton like oxidations processes. J. Hazard. Mater., v.174, p.122-128. 2010.

MICHALSKA, K.; MIAZEK, K.; KRZYSTEK, L.; LEDAKOWICZ, S. Influence of pretreatment with Fenton's reagent on biogas production and methane yield from lignocellulosic biomass. Bioresource Technology, v.119, p.72-78. 2012.

Ministério da Agricultura, Pecuária e Abastecimento (MAPA). (2012). Vegetal. Disponível em: <http://www.agricultura.gov.br/vegetal> Acesso em: ago/2013.

MIN, H.; KYU, S.; HYUB, J.; MOON, J. Bioresource Technology Microbial community structure in a thermophilic aerobic digester used as a sludge pretreatment process for the mesophilic anaerobic digestion and the enhancement of methane production. Bioresource Technology, v. 145, p. 80-89, 2013.

MONTONERI, E.; SAVARINO, P.; BOTTIGLIENGO, S.; BOFFA, V.; PREVOT, A.B.; FABBRI, D.; et al. Biomass wastes as renewable source of energy and chemicals for the industry with friendly environmental impact. Fresenius Environ Bull, v.18, n.2, p.219-223. 2009.

MOURA, J.P. de. Estudo de casos das rotas tecnológicas para produção de biogás e da influência da composição química de dejetos de matrizes suínas na qualidade do biogás gerada por biodigestor. 2012. 122f. Tese (Doutorado em Engenharia Mecânica), Universidade Federal de Pernambuco.

MOSIER, N.; WYMAN, C.; DALE, B.; ELANDER, R.; LEE, Y.Y.; HOLTZAPPLE, M.; et al. Features of promising technologies for pretreatment of lignocellulosic biomass. Bioresour Technol, v.96, n.6, p.673-686. 2005.

NETO, E.D.D.; ALVARENGA, L.H.; et al. Implementação e Avaliação de um Biodigestor de Produção Descontínua. Revista eletrônica E-xacta, v.3, n.2. 2010. 
OLIVEIRA, L.R.P. de. Biodigestor. In: VII Simpósio Goiano de Avicultura e II Simpósio Goiano de Suinocultura. 2005, p. 4-8.

OLIVEIRA, S. V. W. B.Estudo de Viabilidade de Aplicação do Biogás no Ambiente Urbano. FUNDACE, Universidade de São Paulo, Faculdade de Economia e Administração, Ribeirão Preto - SP. 2009.

OZTURK, B.; DEMIRCIYEVA, F. Comparison of biogas upgrading performances of different mixed matrix membranes. Chemical Engineering Journal, v.222, p.209-217. 2013.

PENG, J.; SONG, Y.; WANG, Y.; YUAN, P.; LIU, R. International Biodeterioration \& Biodegradation Spatial succession and metabolic properties of functional microbial communities in an anaerobic baf $\mathrm{fl}$ ed reactor. International Biodeterioration \& Biodegradation, v. 80, p. 60-65, 2013.

QUADROS, D. G. de; et al. Biodigestão anaeróbia de dejetos de caprinos e ovinos los reator contínuo de PVC Flexível. Rev. bras. eng. agríc. ambiente, Campina Grande, v.14, n.3. 2010. QUIRINO, W.F. Utilização energética de resíduos vegetais. Brasília, Laboratório de Produtos Florestais - LPF/IBAMA. 2003, 14p.

REICHERT, G.A.; Aplicação da Digestão Anaeróbia de Resíduos Sólidos Urbanos: Uma Revisão. In: $23^{\circ}$ Congresso Brasileiro de Engenharia Sanitária e Ambiental. Anais... ABES Associação Brasileira de Engenharia Sanitária e Ambiental. Campo Grande - MS. 2005.

SAGULA, A.L. Biodigestão anaeróbia de cama de frango em co-digestão com caldo de cana-de-açúcar. 2012. 69f. Dissertação (Mestrado em Agronomia), Faculdade de Ciências Agrárias da UNESP. Botucatu, São Paulo.

SALOMON, K.R. Avaliação Técnico-Econômica e Ambiental da Utilização do Biogás Proveniente da Biodigestão da Vinhaça em Tecnologias para Geração de Eletricidade. 2007. 247f. Tese (Doutorado em Engenharia),Universidade Federal de Itajubá. Itajubá-MG.

SAPCI, Z.; MORKEN, J.; LINJORDET, R.An Investigation of the Enhancement of Biogas Yields from Lignocellulosic Material using Two Pretreatment Methods: Microwave Irradiation and Steam Explosion. Bio Resources, v.8, n.2, p.1976-1985. 2013.

SATER, O.; SOUZA, N.D.; OLIVEIRA, E.A.G.; ELIAS, T. de F.; TAVARES, R. Estudo comparativo da carbonização de resíduos agrícolas e florestais visando à substituição da lenha no processo de secagem de grãos de café. Rev. Ceres, Viçosa, v.58, n.6, p. 717-722. 2011.

SGORLON, J.G.; RIZK, M.C.; BERGAMASCO, R.; TAVARES, C.R.G.; Avaliação da DQO e da Relação C/N Obtidas no Tratamento Anaeróbio de Resíduos Fruti-hortículas. Acta Scientiarum Technology, v.33, n.4, p.421-424. 2011. 
SILVA, M. S. Biodigestão anaeróbia no saneamento rural. Lavras: UFLA/FAEPE, 71p. (Textos Acadêmicos). 2001.

SOUZA, M.M. de; DA SILVA, D.A.; ROCHADELLI, R.; SANTOS, R.C. Estimativa de poder calorífico e caracterização para uso energético de resíduos da colheita e do processamento de Pinus taeda. FLORESTA, Curitiba, PR, v.42, n.2, p.325-334. 2012.

SUN, Y.; CHENG, J.J. Dilute acid pretreatment of rye straw and bermudagrass for ethaol production. Bioresource Technology, v.96, p.1599-1606. 2005.

TOLMASQUIM, M. T. Perspectivas e Planejamento do Setor energético no Brasil. Estud. av., São Paulo, v.26, n.74, 2012.

TRUGILHO, P.F.; LIMA, J.T.; MENDES, L.M. Influência da idade nas características físicoquímicas e anatômicas da madeira de Eucalyptussaligna. Revista Cerne, Lavras, v.2, n.1, p.94111. 1996.

WALSH, J.L.; ROSS,C.C.; SMITH,M.H.; HARPER,S.R. Utilization of biogas. Biomass, v.20, p.277-290.1989.

WILKIE, A.C.; RIEDESEL, K.J.; OWENS, J.M. Stillage characterization and anaerobictreatment of ethanol stillage from conventional cellulosic feedstocks. Biomass Bioenergy, v.19, p.63-102. 2000. 